\title{
TINGKAT KEBERHASILAN PENGEBORAN DAN PELEDAKAN PADA PEMBONGKARAN TANAH PENUTUP
}

\section{THE SUCCESS LEVEL OF DRILLING AND BLASTING ON OVERBURDEN REMOVAL}

\author{
YY. Hutajulu ${ }^{1}$, Y. Taruna ${ }^{2}$, F F. Lakoy ${ }^{3}$, F. Indrajaya ${ }^{4 *}$, DAK. Wijaya ${ }^{5}$ \\ 1-5 Jurusan/Program Studi Teknik Pertambangan, Fakultas Teknik, Universitas Palangka Raya \\ Kampus UPR Tunjung Nyaho Jalan Yos Sudarso, Palangka Raya 73112 Kalimantan Tengah - INDONESIA \\ e-mail: ${ }^{1}$ yossayonathan@mining.upr.ac.id, ${ }^{2}$ yulian taruna@mining.upr.ac.id, ${ }^{3}$ frangkyengq@gmail.com \\ ${ }^{*}$ fahrulindrajaya@mining.upr.ac.id, ${ }^{5}$ dodywijaya@mining.upr.ac.id
}

\begin{abstract}
ABSTRAK
Faktor yang dapat mempengaruhi kegiatan pengeboran dan peledakan untuk meningkatkan hasil produksi batubara, yaitu aspek teknis, aspek keselamatan, aspek kesehatan serta lingkungan kerja. Rencana target produksi pembongkaran tanah penutup untuk rencana per-hari belum sesuai dengan hasil aktual di lapangan. Penerapan dan penggunaan bahan peledak secara efisien yang digunakan masih kurang baik, sehingga fragmentasi batuan di lapangan sering dijumpai banyak bongkahan besar serta terjadi batu terbang mengakibatkan kondisi tidak aman bagi pekerja dan lingkungan di Pit II Banko Barat. Setiap kali dilakukan peledakan pada tanah penutup akan terdapat batu-batu yang hampir beterbangan, asap gas beracun, dan waktu penggalian yang tidak efektif. Penelitian ini bertujuan untuk menganalisis tingkat keberhasilan pengeboran dan peledakan agar target produksi dapat terpenuhi. Metode penelitian yang digunakan adalah pendekatan secara kuantitatif dengan menggunakan metode likert untuk mengetahui tingkat keberhasilan pengeboran dan peledakan. Hasil analisis menunjukkan bahwa tingkat keberhasilan pengeboran dan peledakan pada pembongkaran tanah penutup di Pit II Banko Barat dengan nilai persentase tingkat keberhasilan sebesar 72,66\% dengan kategori berhasil.
\end{abstract}

Kata kunci: Peledakan, Pengeboran, Pembongkaran Tanah Penutup, Tingkat Keberhasilan

\section{ABSTRACT}

Factors that can influence drilling and blasting activities to increase coal production are technical aspects, safety aspects, health aspects, and work environment. The production for overburden removal planned for the per day plan was not following actual results in the field. The efficient application and use of explosives used were still not good, so rock fragmentation in the field was often found with large boulders and flying stones, resulting in unsafe conditions for workers and the environment in Pit II Banko Barat. Every time the blasting is carried out on the overburden, there will be almost flying stones, poisonous gas fumes, and the digging time that is not effective. This study aims to analyze the levels of drilling and blasting rates so that production targets can be fulfilled. The research method used is a quantitative approach using the Likert method to determine the success rate of drilling and blasting. The results of the analysis show that the success rate of drilling and blasting in overburden removal at Pit II Banko Barat with a percentage value of the success rate is $72.66 \%$ with a successful category.

Keywords: Blasting, Drilling, Overburden Removal, Success Level

\section{PENDAHULUAN}

Salah satu aktivitas penambangan yang diutamakan untuk mencapai target produksi ialah pengupasan lapisan tanah/batuan penutup [1]. Kegiatan pengeboran dan peledakan pada tanah penutup (overburden) dalam meningkatkan target produksi batubara terdapat beberapa faktor yang mempengaruhinya, yaitu aspek teknis, keselamatan dan kesehatan kerja, dampaknya terhadap lingkungan [2]. Selain menggunakan alat mekanis untuk 
mengupas material lunak, digunakan juga proses peledakan untuk memberaikan tanah/batuan penutup yang sifatnya material keras [3]. Ada beberapa bentuk indikator keberhasilan dalam pengeboran dan peledakan itu sendiri, yaitu tercapai target dari pembongkaran tanah penutup untuk mendapatkan produksi batubara yang optimal [4]. Hal tersebut seringkali menimbulkan masalah dalam kegiatan peledakan. Pembongkaran tanah penutup maupun antar lapisan penutup dengan melakukan peledakan [5-6]. Rencana produksi tanah penutup yang dibongkar menggunakan sistem pengeboran dan peledakan dalam sehari masih belum optimal [7]. Keberhasilan peledakan biasanya dapat dilihat dari ukuran fragmen batuan yang dihasilkan [8].

Penggunaan bahan peledak yang kurang efisien pada area Pit II Banko Barat PT Bukit Asam masih belum maksimal, disebabkan terdapat bongkahan besar dan fragmentasi batuan akibat kegiatan peledakan, kondisi yang tidak aman bagi pekerja dan lingkungan [9-10]. Dalam kegiatan penambangan proses pengeboran dan peledakan terhadap tanah/batuan penutup merupakan salah satu dari tahapan operasi produksi [11]. Hal ini tidak baik jika sering ada batuan terbang (flying rock), gas beracun (asap), dan waktu penggalian yang tidak efektif [6,12]. Pengaruh kedalaman pengeboran dan fragmentasi hasil peledakan tidak akan tercapai apabila hasil perolehannya tidak optimal [13].

Penelitian ini sangat mendasar karena fenomena yang sering terjadi di lapangan, yaitu penggunaan bahan peledak yang tidak efisien dan berlebihan dengan membutuhkan biaya besar serta hasil fragmentasi peledakannya yang tidak merata (terdapat bongkahan besar dan kecil). Kegiatan pembongkaran yang terbebani tidak terlepas dari kegiatan pengeboran dan peledakan [14]. Dengan melakukan teknik penilaian keberhasilan menggunakan skala Likert [15], maka akan mendapatkan persentase interval hasil peledakan yang diterapkan sehingga kelemahan dan kelebihan aktivitas peledakan dapat diketahui. Parameter yang kurang berhasil dapat ditingkatkan menjadi sangat berhasil dengan mengoptimalkan pengisian bahan peledak yang efisien dengan biaya yang menguntungkan dan menghasilkan fragmentasi yang merata, sehingga lebih mudah untuk memuat dan menggali yang dilakukan oleh alat gali muat. Penelitian ini bertujuan untuk menganalisis tingkat keberhasilan pengeboran dan peledakan agar target produksi dapat terpenuhi.

\section{METODE PENELITIAN}

Metode penelitian yang digunakan dengan pendekatan kuantitatif dan penggunaan data sekunder terhadap nilai persentasi keberhasilan pengeboran dan peledakan.
Metode pengambilan data yang akan dilakukan dengan pengamatan langsung di lapangan terhadap operasional drilling dan blasting. Pengambilan data diambil langsung di lapangan meliputi data proses kegiatan pengeboran, isian bahan peledak dan fragmentasi batuan.

Lokasi penelitian dan pengambilan data dilakukan pada satuan kerja penanganan pengupasan tanah penutup (overburden) Pit II Banko Barat yang berada di PT Bukit Asam Tbk.

Analisis data dilakukan dengan melakukan beberapa perhitungan penilaian dan persentase keberhasilan dengan menggunakan pendekatan Skala Likert [16]. Masing-masing parameter tingkat keberhasilan pengeboran dan peledakan diberikan scoring. Dalam sistem penilaian dapat ditentukan, semakin tinggi skala pengukuran yang digunakan maka hasilnya lebih halus dan akurat. Untuk scoring pada tingkat keberhasilan menggunakan angka dari 1 - 5 menurut [17], di mana :

$$
\begin{aligned}
& 1=\text { Sangat rendah } \\
& 2=\text { Rendah } \\
& 3=\text { Cukup Rendah } \\
& 4=\text { Tinggi } \\
& 5=\text { Sangat Tinggi }
\end{aligned}
$$

Scoring diterapkan dengan memberikan nilai maksimum 5, dan sebagai nilai tengah (median) diberi nilai 3 dan nilai terendah diberikan nilai 1 . Dengan mengetahui interval pertama (kisaran jarak) dan interpretasi persen untuk mengetahui penilaian dengan menemukan nilai skor persen interval (I).

Rumus Interval :

$$
\begin{array}{ll}
\text { I } & =100 / \text { Jumlah Skor } \\
\text { Maka } & =100 / 5=20
\end{array}
$$

Hasil (I) $=20$

(Ini adalah intervalnya jarak dari terendah $0 \%$ hingga tertinggi $100 \%$ ). Berikut ini adalah kriteria interpretasi berdasarkan interval (Tabel 1).

Tabel 1. Persentase tingkat keberhasilan

\begin{tabular}{|c|c|c|}
\hline No & Persentase $\%$ & Kategori \\
\hline 1. & $0-19,99$ & Tidak Berhasil \\
\hline 2. & $20-39,99$ & Kurang Berhasil \\
\hline 3. & $40-59,99$ & Cukup Berhasil \\
\hline 4. & $60-79,99$ & Berhasil \\
\hline 5. & $80-100$ & Sangat Berhasil \\
\hline
\end{tabular}

Setelah menilai keberhasilan berdasarkan lapangan, maka untuk mengetahui hasil dari nilai parameterparameter tingkat keberhasilan pengeboran dan peledakan di lapisan tanah penutup pada Pit II Banko Barat berdasarkan perhitungan menggunakan Pers.(1) yaitu target pembongkaran terpenuhi $(\mathrm{OB})$ : 
$R I \%=\left(\frac{\mathrm{TS}}{Y} \times 100\right)$

Keterangan :

RI : Rumus Index \%

TS : Total Skor

Y : Skor Tertinggi x Jumlah/banyaknya Data

\section{HASIL DAN PEMBAHASAN}

Tujuan utama aktivitas peledakan di area Pit II Banko Barat, yaitu untuk menghilangkan material tanah dari batuan induknya dengan peregangan semua material terberai sempurna dan bersifat lepas (lose). Sebelum dilakukan peledakan, terlebih dahulu melakukan penitikan pada lubang bor dalam satu pola pengeboran.

Peledakan dilakukan di daerah Pit II Barat Banko untuk memenuhi target produksi peledakan harian. Detonasi target per hari di pit II Barat Banko, yaitu 20.000 $\mathrm{BCM} /$ peledakan. Untuk aktual data pada hasil peledakan per hari menggunakan alat berat dari Komatsu 3000 PC Power Shovel. Kemudian data hasil aktual volume harian dibandingkan dengan rencana produksi peledakan harian.

\section{Target Produksi}

Target produksi akan terpenuhi jika target harian aktual adalah $>98 \%$. Hasil dari pencapaian produksi peledakan aktual harian adalah tiga kali dengan frekuensi detonasi yang memiliki nilai terendah karena volume yang didapatkan kurang dari rencana volume harian. Berdasarkan jumlah dari semua volume harian aktual selama sepuluh hari, detonasi diperoleh sebesar 206.773,91 BCM/bulan. Untuk data aktual, volume detonasi diambil dari data volume alat berat Power Shovel PC 3000. Tabel 2 menunjukan ketercapaian target pembongkaran.

Tabel 2. Target pembongkaran terpenuhi

\begin{tabular}{|c|c|c|c|c|}
\hline No. & $\begin{array}{c}\text { Plan Blasting } \\
\text { Harian } \\
\text { (BCM/ } \\
\text { Peledakan) }\end{array}$ & $\begin{array}{c}\text { Volume } \\
\text { Blasting } \\
\text { Geometri } \\
(\text { BCM) }\end{array}$ & $\begin{array}{c}\text { Volume Alat } \\
\text { PC 3000 } \\
\text { (BCM/ } \\
\text { Peledakan) }\end{array}$ & $\begin{array}{c}\text { Pencapaian } \\
\text { Volume } \\
\text { Aktual (\%) }\end{array}$ \\
\hline 1. & 20.000 & $16.516,5$ & $17.608,5$ & 88 \\
\hline 2. & 20.000 & 15.210 & $16.350,75$ & 81 \\
\hline 3. & 20.000 & $20.793,63$ & 20.124 & 100 \\
\hline 4. & 20.000 & $12.080,25$ & $14.212,57$ & 71 \\
\hline 5. & 20.000 & $15.551,25$ & $16.350,57$ & 81 \\
\hline 6. & 20.000 & $21.188,8$ & $22.639,5$ & 113 \\
\hline 7. & 20.000 & 22.638 & $23.268,37$ & 116 \\
\hline 8. & 20.000 & $24.085,1$ & 25.155 & 125 \\
\hline 9. & 20.000 & $27.320,8$ & $27.670,5$ & 138 \\
\hline 10. & 20.000 & $22.282,2$ & $23.394,15$ & 116 \\
\hline Jumlah & 200.000 & $189.802,31$ & $206.773,91 \mathrm{BCM} /$ Bulan \\
\hline
\end{tabular}

Tabel 2 menunjukkan bahwa total skor target pembongkaran terpenuhi menghasilkan skor 45. Nilai tingkat keberhasilan adalah 90\% (sangat berhasil).

\section{Penggunaan Bahan Peledak Efisien}

Efisiensi dalam pemakaian bahan peledak menyatakan jumlah batuan sukses dibongkar per kilogram bahan peledak. Faktor bubuk (powder factor) merupakan bahan peledak yang digunakan untuk meledakkan volume batuan. Pada daerah Pit II Banko Barat, powder factor (PF) yang digunakan selama frekuensi peledakan di tahun 2020 tepatnya bulan maret, yaitu berkisar 0,12 $0,18 \mathrm{~kg} / \mathrm{BCM}$ dengan rata-rata penggunaan powder factor pada bulan maret sebesar $0,15 \mathrm{~kg} / \mathrm{BCM}$ dengan waktu penggalian sekitar $<12$ detik (Tabel 3). Penggunaan Ammonium Nitrate (AN) sebanyak 26.720 $\mathrm{kg}$ dan penggunaan Fuel Oil (FO) sebanyak 1.555,13 liter.

Tabel 3. Parameter penggunaan bahan peledak

\begin{tabular}{|c|c|c|c|c|c|c|}
\hline \multirow{2}{*}{ No } & PF & \multirow{2}{*}{ Volume } & \multirow{2}{*}{$\begin{array}{c}\text { AN } \\
\text { Aktual }\end{array}$} & \multirow{2}{*}{$\begin{array}{c}\text { PF } \\
\text { Aktual }\end{array}$} & Digging & \multirow{2}{*}{ Nilai } \\
\hline & Plan & & & & Time & \\
\hline 1. & 0,12 & $16.516,50$ & 2.475 & 0,15 & 10,39 & 3 \\
\hline 2. & 0,12 & 15.210 & 2.700 & 0,17 & 13,35 & 1 \\
\hline 3. & 0,12 & $20.793,63$ & 2.920 & 0,14 & 9,51 & 2 \\
\hline 4. & 0,12 & $13.639,70$ & 2.025 & 0,18 & 12,38 & 2 \\
\hline 5. & 0,12 & $15.765,80$ & 2.750 & 0,18 & 14,33 & 1 \\
\hline 6. & 0,12 & $21.188,80$ & 2.500 & 0,12 & 10 & 5 \\
\hline 7. & 0,12 & 22.638 & 2.500 & 0,11 & 12,48 & 4 \\
\hline 8. & 0,12 & $24.085,10$ & 2.750 & 0,12 & 14,5 & 3 \\
\hline 9. & 0,12 & $27.320,80$ & 3.600 & 0,13 & 9,11 & 2 \\
\hline 10. & 0,12 & $22.282,20$ & 2.750 & 0,18 & 9,4 & 2 \\
\hline
\end{tabular}

Total skor dalam penggunaan bahan peledak menghasilkan skor 25 dengan nilai tingkat keberhasilan $50 \%$ (cukup berhasil).

Fragmentasi Batuan

Fragmentasi batuan dicapai secara merata dengan potongan kecil (kurang dari 15\% batuan terbongkar). Suatu operasi pengeboran dan peledakan dinyatakan berhasil jika fragmentasi hasil peledakan berukuran merata sehingga sedikit bongkah dengan persentase kurang dari 15\% untuk material boulder (Gambar 1).

Fragmentasi peledakan pada area Banko Barat Pit II terdapat beberapa frekuensi peledakan dimana potongan fragmentasi masih diatas $15 \%$ untuk ukuran $100 \mathrm{~cm}$. Hal ini disebabkan seringnya pelontaran stemming, dan lokasinya memiliki perbedaan ketinggian dan tidak rata. 
Dalam penentuan powder factor untuk lapisan sandstone selama penggunaan bahan peledak adalah $0,15 \mathrm{~kg} / \mathrm{BCM}$ dengan persentase fragmentasi $33,62 \%$ dan $\mathrm{PF}$ sebesar $0,18 \mathrm{~kg} / \mathrm{BCM}$ dengan fragmentasi $33,18 \%$. Perhitungan skor terhadap fragmentasi peledakan menghasilkan nilai 10 dengan tingkat keberhasilan 20\% (kurang berhasil).

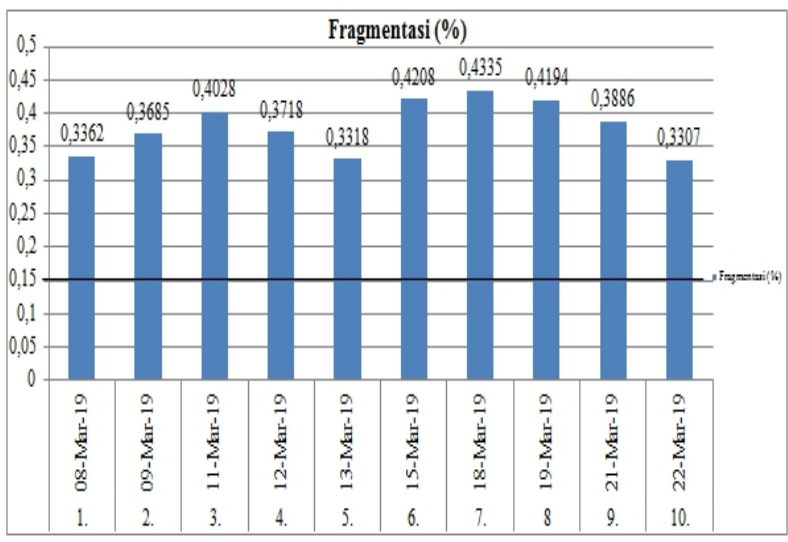

Gambar 1. Hasil fragmentasi peledakan

Parameter Aman

Tingkat keberhasilan untuk parameter aman tanpa misfire diberikan 5 poin. Jika diledakkan, ada tindakan tidak aman (misfire) < dari 5 lubang diberikan nilai 4 . Hasil perhitungan terhadap keseluruhan menghasilkan skor 49 dengan tingkat keberhasilan yang dicapai adalah 98\% (sangat berhasil). Hal ini dikarenakan kegiatan pemboran dan peledakan merupakan kegiatan yang beresiko tinggi (highrisk), sehingga dibutuhkan penanganan khusus, pengawasan yang ketat, dan disiplin yang tinggi terhadap awak pemboran dan peledakan untuk menghindari atau meminimalisir kecelakaan di lapangan selama kegiatan pemboran dan peledakan agar tidak menimbulkan kerugian, baik dari perusahaan maupun tim itu sendiri.

Untuk meminimalisir terjadinya kecelakaan di area kerja, maka dikeluarkanlah Standard Operating Procedures (SOP) untuk berfungsi sebagai pedoman yang harus dipatuhi oleh awak pengeboran dan peledakan. Dari SOP ini terdapat 4 (empat) proses / tindakan yang dilarang dalam suatu kegiatan:

1. Tidak memakai APD (safety helmet, safety shoes dan safety vest/reflektor)

2. Misfire (Kebakaran)

3. Merokok dalam area pengeboran dan peledakan

4. Berada di jarak tidak aman untuk unit dan manusia
Batuan Terbang (flyingrock)

Pengambilan data flying rock di lapangan untuk mengurangi jarak evakuasi dari 300 meter menjadi 200 meter untuk jarak aman perangkat/unit pada saat ledakan dengan kedalaman eksplosif di atas 6 meter dan kondisi lubang kering datar, tetapi untuk peledakan di lubang peledak pendek dan lubang penyiraman dengan kedalaman di bawah 6 meter untuk jarak evakuasi dikembalikan ke 300 meter. Peledakan lubang pipa pendek, batu terbang flyrock dilemparkan hingga 229 meter (Tabel 4).

Hasil perhitungan terhadap keseluruhan menghasilkan skor 39 dengan tingkat keberhasilan yang dicapai adalah $78 \%$ (berhasil).

Tabel 4. Parameter batu terbang (flyrock)

\begin{tabular}{|c|c|c|c|c|c|c|c|}
\hline \multicolumn{2}{|c|}{ Lokasi Peledakan } & \multirow{2}{*}{$\begin{array}{c}\text { B } \\
(\mathrm{m})\end{array}$} & \multirow{2}{*}{$\begin{array}{c}\mathrm{S} \\
(\mathrm{m})\end{array}$} & \multirow{2}{*}{$\begin{array}{c}\text { Depth } \\
(\mathrm{m})\end{array}$} & \multirow{2}{*}{$\mathrm{N}$} & \multirow{2}{*}{$\begin{array}{c}\mathrm{PF} \\
(\mathrm{kg} / \mathrm{bcm})\end{array}$} & \multirow{2}{*}{$\begin{array}{l}\text { Flyrock } \\
\text { (m) }\end{array}$} \\
\hline Blok & Pit & & & & & & \\
\hline \multirow{10}{*}{$\begin{array}{c}\text { Banko } \\
\text { Barat }\end{array}$} & Pit II & 6,4 & 7 & 6,6 & 55 & 0,15 & 157 \\
\hline & Pit II & 6,5 & 6,5 & 6 & 60 & 0,17 & 106 \\
\hline & Pit II & 6,6 & 7,4 & 6,5 & 65 & 0,14 & 57 \\
\hline & Pit II & 6,5 & 7 & 5,9 & 45 & 0,17 & 217 \\
\hline & Pit II & 6,5 & 7,5 & 5,8 & 55 & 0,18 & 224 \\
\hline & Pit II & 7,6 & 8,2 & 6,8 & 50 & 0,12 & 33,23 \\
\hline & Pit II & 7,7 & 8,4 & 7 & 50 & 0,11 & 14 \\
\hline & Pit II & 7,6 & 8,6 & 6,7 & 55 & 0,12 & 24 \\
\hline & Pit II & 6,5 & 7,4 & 7 & 80 & 0,13 & 20,5 \\
\hline & Pit II & 6,4 & 6,4 & 6,7 & 55 & 0,18 & 176 \\
\hline
\end{tabular}

Keuntungan dalam mengurangi jarak evakuasi unit kemungkinan dapat menghemat bahan bakar dan mengurangi waktu keterlambatan perjalanan unit untuk kembali ke posisi area pemuatan. Gambar 2 menunjukan jarak lemparan batuan akibat hasil peledakan.

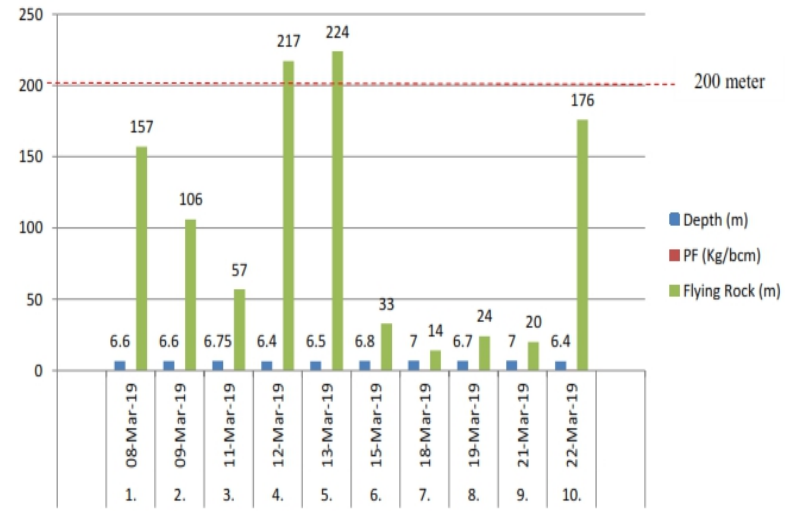

Gambar 2. Jarak lemparan batuan akibat hasil peledakan 


\section{Getaran Tanah}

Getaran tanah yang terjadi Pada ledakan di Pit II West Banko PT Bukit Asam Tbk tidak menjadi masalah karena jarak lokasi tambang dengan kawasan pemukiman terpencil dengan jarak 1 - 1,8 km di Desa Tanjung Enim. Pengukuran getaran blast result pada jarak 500 - 1000 meter sebagai prosedur peledakan standar yang telah ditetapkan.

Getaran efek tanah dari peledakan pada tambang terbuka, yaitu bangunan kuno ( $2 \mathrm{~mm} /$ detik), bangunan dengan fondasi pasangan batu bata dan campuran semen hanya ( $3 \mathrm{~mm} /$ detik), Bangunan dengan fondasi pasangan batu bata dan campuran semen yang diikat dengan kemiringan beton $(5 \mathrm{~mm} /$ detik). Skor getaran terendah dari efek ledakan lebih dari ( $2 \mathrm{~mm} /$ detik). Tabel 5 menunjukan hasil pengukuram getaran tanah setelah peledakan.

Tabel 5. Hasil pengukuran getaran tanah setelah peledakan

\begin{tabular}{|c|c|c|c|c|c|c|c|}
\hline \multicolumn{2}{|c|}{ Lokasi Peledakan } & \multirow{2}{*}{$\begin{array}{c}\mathrm{B} \\
(\mathrm{m})\end{array}$} & \multirow{2}{*}{$\begin{array}{c}\mathrm{S} \\
(\mathrm{m})\end{array}$} & \multirow{2}{*}{$\begin{array}{c}\text { Depth } \\
\text { (m) }\end{array}$} & \multirow{2}{*}{$\begin{array}{c}\mathrm{PF} \\
(\mathrm{kg} / \mathrm{b} \\
\mathrm{cm})\end{array}$} & \multirow{2}{*}{$\begin{array}{l}\text { Total } \\
\text { Hole }\end{array}$} & \multirow{2}{*}{$\begin{array}{c}\text { Getaran } \\
(\mathrm{mm} / \mathrm{s})\end{array}$} \\
\hline Blok & Pit & & & & & & \\
\hline \multirow{10}{*}{$\begin{array}{c}\text { Banko } \\
\text { Barat }\end{array}$} & Pit II & 6,4 & 7 & 6,6 & 0,15 & 55 & 0,50 \\
\hline & Pit II & 6,5 & 6,5 & 6 & 0,17 & 60 & 0,50 \\
\hline & Pit II & 6,6 & 7,4 & 6,5 & 0,14 & 65 & 0,54 \\
\hline & Pit II & 6,5 & 7 & 5,9 & 0,17 & 45 & 0,69 \\
\hline & Pit II & 6,5 & 7,5 & 5,8 & 0,18 & 55 & 0,66 \\
\hline & Pit II & 7,6 & 8,2 & 6,8 & 0,12 & 50 & 0,50 \\
\hline & Pit II & 7,7 & 8,4 & 7 & 0,11 & 50 & 0,57 \\
\hline & Pit II & 7,6 & 8,6 & 6,7 & 0,12 & 55 & 0,73 \\
\hline & Pit II & 6,5 & 7,4 & 7 & 0,13 & 80 & 0,78 \\
\hline & Pit II & 6,4 & 6,4 & 6,4 & 0,18 & 55 & 0,78 \\
\hline
\end{tabular}

Hasil perhitungan nilai skor terhadap getaran (ground vibration) adalah 50, dengan tingkat keberhasilan yang dicapai 100\% (sangat berhasil).

\section{Kebisingan}

Menurut [18] kualitas kebisingan standar, SNI 7570 pada tahun 2010 untuk suara ledakan di tambang terbuka adalah $110 \mathrm{~dB}$. Jadi untuk skor terendah, jika suara ledakan lebih dari $110 \mathrm{~dB}$. Berdasarkan hasil penilaian parameter kebisingan selama periode studi, hasil peledakan masih sangat stabil. Mereka tidak mengganggu masyarakat untuk menjadi sasaran tingkat kebisingan dari hasil peledakan yang tidak lulus dari standar yang ditetapkan oleh Standar Nasional Indonesia (SNI) sebesar $110 \mathrm{~dB}$. Gambar 3 merupakan hasil pengukuran kebisingan selama peledakan.

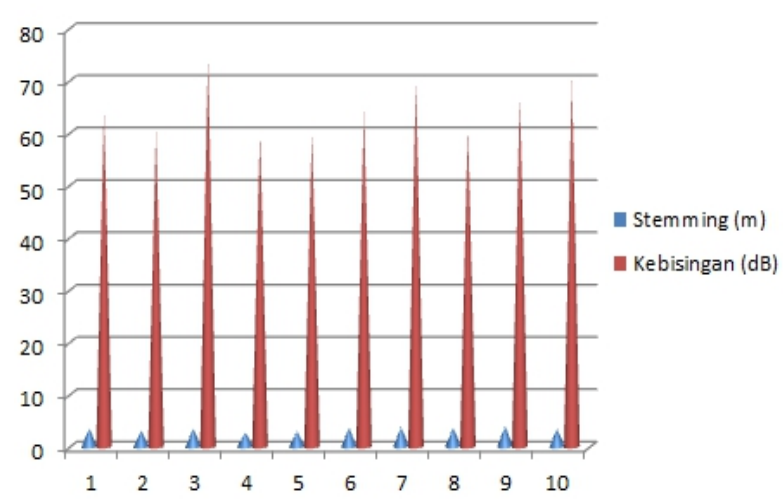

Gambar 3. Pengukuran kebisingan selama peledakan

Perhitungan nilai skor terhadap kebisingan yang dihasilkan dari proses peledakan adalah 50, dengan tingkat keberhasilan yang dicapai 100\% (sangat berhasil).

Gas Beracun

Reaksi peledakan menghasilkan gas tertentu yang beracun dan tidak beracun. Ada 3 jenis gas hasil peledakan, yaitu zero oxygen balance (tidak berwarna/asap putih), smoke (asap hitam) yang diberikan nilai 2 , pada asap terdapat 3 tingkat warna, yaitu kuning diberikan nilai 3 , debiran oranye dengan nilai 2 . Tingkat tertinggi gas beracun berbahaya yang asap berwarna merah diberikan nilai 1. Dari hasil pengambilan data di lapangan, beberapa frekuensi peledakan menghasilkan smoke dan Fumes (Gambar 4).

Perhitungan nilai skor terhadap gas beracun yang dihasilkan dari proses peledakan adalah 29, dengan tingkat keberhasilan yang mencapai 58\% (cukup berhasil).

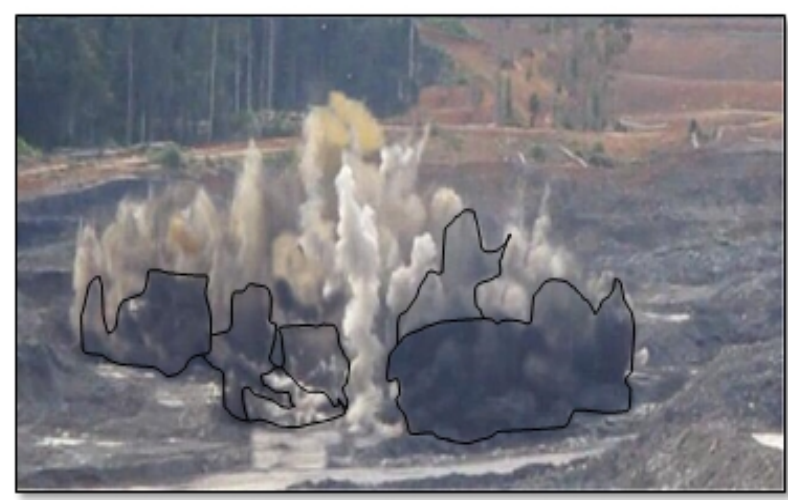

Gambar 4. Hasil peledakan asap berwarna hitam keabuan 
Untuk asap dengan gas hitam keabu-abuan dan asap dengan gas berwarna oranye kekuningan (Gambar 5).

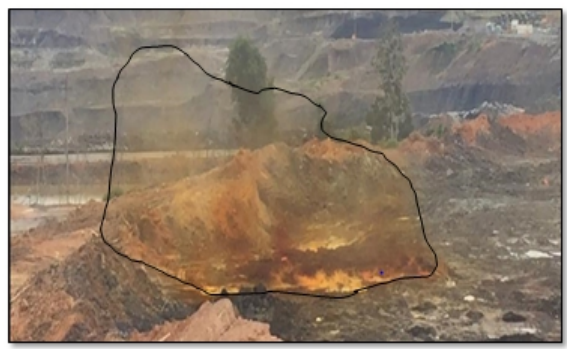

Gambar 5. Hasil peledakan berupa fumes berwarna orange

\section{Waktu Penggalian (Digging Time)}

Keberhasilan dalam kegiatan pengeboran dan peledakan dapat dilihat dari waktu penggalian alat pemuat hingga penggalian fragmentasi hasil peledakan. Waktu penggalian menggunakan alat Komatsu PC 3000 adalah $\leq 12$ detik dengan nilai 5. Nilai PF sudah besar tetapi tidak dapat menentukan waktu penggalian yang singkat.

Hasil korelasi (Gambar 6) menyatakan bahwa meskipun nilai PF sudah besar, itu tidak dapat menentukan waktu penggalian menjadi singkat. Pada nilai PF $0,12 \mathrm{~kg} / \mathrm{BCM}$ dan $0,17 \mathrm{~kg} / \mathrm{BCM}$, waktu gali di PF $0,12 \mathrm{~kg} / \mathrm{bcm}$ lebih pendek dengan waktu gali selama 10 detik, sedangkan pada PF $0,17 \mathrm{~kg} / \mathrm{BCM}$ dengan waktu gali selama 13,35 detik. Hal ini disebabkan perbedaan karakteristik jenis batuan yang digali oleh loader. Namun intinya, semakin besar PF, semakin panjang waktu penggalian yang dibutuhkan. Total skor yang dihasilkan waktu penggalian adalah 30, dengan tingkat keberhasilan yang dicapai sebesar $60 \%$.

PENGARUH PF TERHADAP DIGGING TIME

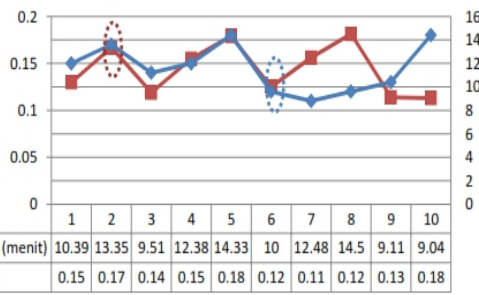

Gambar 6. Pengaruh PF terhadap waktu penggalian

Analisis tingkat keberhasilan parameter target produksi lapisan penutup telah terpenuhi, penggunaan bahan peledak yang efisien, fragmentasi batuan yang berukuran merata dengan bongkahan yang lebih sedikit (kurang dari
$15 \%$ jumlah batuan yang dibongkar per ledakan), aman dalam kondisi tidak ada kecelakaan, tidak adanya dua frekuensi ledakan yang mengakibatkan batuan terbang lebih dari 200 meter, getaran, kebisingan, gas beracun bawang merah di setiap frekuensi ledakan, dan waktu penggalian. Dengan demikian, analisis tingkat keberhasilan pengeboran dan peledakan pada pembongkaran tanah penutup (overburden) di Pit II Banko Barat PTBA tahun 2019, dapat disimpulkan nilai persentase dari tingkat keberhasilan semua parameter adalah 72,66\% dengan kategori berhasil (Tabel 6).

Tabel 6. Nilai tingkat keberhasilan

\begin{tabular}{|c|c|c|c|}
\hline $\begin{array}{c}\text { Parameter } \\
\text { Tingkat } \\
\text { Keberhasilan }\end{array}$ & $\begin{array}{l}\text { Total } \\
\text { Skor }\end{array}$ & $\begin{array}{c}\text { Niai Tingkat } \\
\text { Keberhasilan } \\
(\%)\end{array}$ & Katerangan \\
\hline $\begin{array}{c}\text { Target } \\
\text { Pembongkaran } \\
\text { Terpenuhi }(\mathrm{OB})\end{array}$ & 45 & $90 \%$ & $\begin{array}{l}\text { Sangat } \\
\text { Berhasil }\end{array}$ \\
\hline $\begin{array}{c}\text { Penggunaan } \\
\text { Bahan Peledak } \\
\text { Efisien } \\
\end{array}$ & 25 & $50 \%$ & $\begin{array}{l}\text { Cukup } \\
\text { Berhasil }\end{array}$ \\
\hline Fragmentasi & 10 & $20 \%$ & $\begin{array}{l}\text { Kurang } \\
\text { Berhasil }\end{array}$ \\
\hline Aman & 49 & $98 \%$ & $\begin{array}{c}\text { Sangat } \\
\text { Berhasil }\end{array}$ \\
\hline $\begin{array}{c}\text { Batu Terbang } \\
\text { (Flyrock) }\end{array}$ & 39 & $78 \%$ & Berhasil \\
\hline $\begin{array}{c}\text { Getaran(Ground } \\
\text { Vibration) }\end{array}$ & 50 & $100 \%$ & $\begin{array}{c}\text { Sangat } \\
\text { Berhasil }\end{array}$ \\
\hline $\begin{array}{c}\text { Kebisisngan (Air } \\
\text { Blast) }\end{array}$ & 50 & $100 \%$ & $\begin{array}{c}\text { Sangat } \\
\text { Berhasil }\end{array}$ \\
\hline Gas Beracun & 29 & $58 \%$ & $\begin{array}{l}\text { Cukup } \\
\text { Berhasil }\end{array}$ \\
\hline Digging Time & 30 & $60 \%$ & Berhasil \\
\hline \multicolumn{2}{|c|}{$\begin{array}{l}\text { Untuk Nillai Tingkat } \\
\text { Keberhasilan drilling dan } \\
\text { blasting dari semua para- } \\
\text { meter didapatkan: }\end{array}$} & $72,66 \%$ & Berhasil \\
\hline
\end{tabular}

Meskipun berhasil berdasarkan semua parameter menurut nilai yang diinginkan harus mencapai 90\%, sehingga nilai persentase di Pit II Banko Barat PT Bukit Asam Tbk tidak dapat dikatakan berhasil karena $<90 \%$. Hal ini disebabkan oleh stemming ejection atau kenaikan primer ke permukaan lubang pipa sehingga dapat mempengaruhi fragmentasi dan penggalian waktu lama. Batu terbang terjadi karena adanya permukaan lubang ledak yang kotor dan penguncian stemming yang kurang tepat. Terjadi gas beracun akibat percampuran AN (Ammonium Nitrat) dan FO (Fuel Oil) yang tidak merata karena Mobile Mixing/Manufacturing Unit (MMU) milik PT Dahana Persero masih menggunakan Mobile Mixing/Manufacturing Unit secara manual atau tanpa alat ukur. 


\section{KESIMPULAN}

Tingkat keberhasilan pengeboran dan peledakan dipengaruhi oleh beberapa faktor, yaitu target produksi dapat dipenuhi, jumlah bahan peledak yang digunakan secara efisien cukup berhasil, dan hasil fragmentasi dikategorikan sebagai masih kurang berhasil karena ada beberapa frekuensi peledakan masih ada bongkahan. Aktivitas yang aman tanpa adanya kecelakaan sangat berhasil, dan efek peledakan dapat dikontrol, seperti batu terbang dan getaran yang sangat sukses. Dari semua parameter di atas yang dapat disimpulkan bahwa nilai tingkat keberhasilan pengeboran dan peledakan pada pembongkaran tanah penutup di Pit II Banko Barat PT Bukit Asam Tbk adalah 72,66\% dengan kategori berhasil. Walaupun berhasil berdasarkan dari semua parameter-parameter, tetapi nilai yang diinginkan oleh perusahaan PT Bukit Asam Tbk harus mencapai >90\% sehingga dapat dikatakan tidak berhasil.

\section{UCAPAN TERIMA KASIH}

Kami berterima kasih kepada PT Bukit Asam Tbk yang telah menyediakan tempat untuk penelitian di lapangan. Kami juga mengucapkan banyak terimakasih kepada Program Studi Teknik Pertambangan Universitas Palangka Raya yang telah memberi dukungan dalam bentuk legalitas dan membantu selama kerja di lapangan serta dalam analisis data terhadap penelitian ini.

\section{DAFTAR PUSTAKA}

[1] Munawir, M., Samanlagi, A. I., \& Anshariah, A. (2015). Analisis Geometri Peledakan Terhadap Ukuran Fragmentasi Overburden Pada Tambang Batubara PT. Pamapersada Nusantara Jobsite Adaro Kalimantan Selatan. Jurnal Geomine, 01(1), 9-13.

[2] Zaidan, A., Nurhakim, N., Riswan, R., \& Isabella, M. (2018). Analisis Ground Vibration Pada Pembongkaran Overburden Terhadap Pemukiman Penduduk di Pit Paringin PT. Bukit Makmur Mandiri Utama Jobsite PT. Adaro Indonesia. Jurnal Geosapta, 4(2), 8597.

[3] Safarudin, S., Purwanto, P., \& Djamaluddin, D. (2016). Analisis Pengaruh Geometri Peledakan Terhadap Fragmentasi dan Digging Time Material Blasting. JPE, 20(2), 54-62.

[4] Cahyadi, M. I., \& Kopa, R. (2018). Evaluasi Rancangan Geometri Peledakan Berdasarkan Hasil Fragmentasi Batuan dan Getaran Tanah Pada PT . Koto Alam Sejahtera Kabupaten Lima Puluh Kota Provinsi Sumatera. Jurnal
Bina Tambang, 4(1), 140-152.

[5] Husni, A., Toha, M. T., \& Komar, S. (2020). Effect Fragmentation and Soil Vibration Due to Blasting to the Productivity and Slope Stability, Jurnal Pertambangan, 4(3), 163167.

[6] Wardhana, F., Toha, M. T., \& Juniah, R. (2020). Analisis Getaran Peledakan Menggunakan Bahan Peledak Emulsion Untuk Meningkatkan Cadangan Tertambang. Jurnal Pertambangan, 04(01), 37-42.

[7] Purwandanu, A. E., Toha, M. T., \& Bochori, B. (2020). Parameter yang Mempengaruhi Produktivitas Pengeboran, Peledakan, dan Sistem Shovel-Dump Truck Pada Tambang Andesit. Jurnal Pertambangan, 4(2), 81-89.

[8] Syafi'i, A. A., Riswan, R., Saismana, U., Hakim, R. N., \& Kartini, K. (2019). Evaluasi Isian Bahan Peledak Menggunakan Analisis Distribusi Ukuran Fragmen Pada Peledakan Batuan Penutup Di Tambang Terbuka Batubara. Jurnal Himasapta, 1(1), 17-22.

[9] Pratama DS, Sudarmono D, Iskandar H. (2015). Pengaruh Powder Factor Peledakan Terhadap Produktivitas Backhoe Komatsu PC 2000 di PT. Bukit Asam (Persero) Tbk. Jurnal Ilmu Tek, 3(1).

[10] Rafliansyah M, Irvani, Oktarianty H. (2020). Analisis Penggunaan Powder Factor Terhadap Fragmentasi pada Lubang Ledak Vertikal dan Inclined di PT Aditya Buana Inter. Mineral, 4(2), 65-71.

[11] Indrajaya, F., Natallia, A. L., \& Sukmawatie, N. (2020). Perancangan Sequence Penambangan Batubara pada PT XYZ Provinsi Sumatera Selatan. Jurnal Geomine, 7(3), 230-240.

[12] Sujiman, Hasyim I, Putra A. (2014). Kajian Geometri Peledakan Terhadap Fragmentasi Batuan Hasil Peledakan Di Pit 4 Tuc Pt. Mega Prima Persada Kecamatan Loa Kulu Kutai Kartanegara Kalimantan Timur. $J$ Geol Pertamb, 2(16), 1-13.

[13] Cahyadi, A. (2011). Kajian Teknis Operasi Peledakan untuk Meningkatkan Nilai Perolehan Hasil Peledakan di Tambang Batubara Kab. Kutai Kartanegara Provinsi Kalimantan Timur. Seminar Nasional Kebumian, 69-76.

[14] Frianto, R., Nurhakim, N., \& Riswan, R. (2017). Kajian Teknis Geometri Peledakan Pada Keberhasilan Pembongkaran Overburden Berdasarkan Fragmentasi Hasil Peledakan. Jurnal Fisika Flux: Jurnal Ilmiah Fisika FMIPA Universitas Lambung Mangkurat, 11(1), 56-67.

[15] Indrajaya, F., L, M. F. T., Fidayanti, N., \& Hutajulu, 
Y. Y. (2020). Assessment of The Reclamation Success At The Northern Serujan Pit in PT. IMK Murung Raya Regency Jurnal. PROMINE, 8(1), 22-27.

[16] Sugiyono, P. (2015). Metode penelitian kombinasi (mixed methods). Bandung: Alfabeta.

[17] Aprilia, K and Ghozali, I. (2013). Teknik Penyusunan Skala Likert dalam Penelitian Akuntansi dan Bisnis. Semarang: Fatawa Publishing.

[18] Marmer, D.,Simangunsong, G. M.,Suwandhi, A. (2010). Peranan SNI 7571:2010 dan SNI 7570: 2010 dalam Kegiatan Peledakan di Tambang Terbuka di Indonesia, Volume 11. 